


\title{
LECTURAS DEL DESIERTO: NUEVAS PROPUESTAS POÉTICAS EN ESPAÑA
}

\author{
MONOGRÁFICO
}

LÓPEZ FERNÁNDEZ, ÁLVARO

UNIVERSIDAD COMPLUTENSE DE MADRID (ESPAÑA) alfernandez@ucm.es

MARTínEZ FERNÁNDEZ, ÁNGELA

UNIVERSITAT DE VALÈNCIA (ESPAÑA) anmarfe6@uv.es

MOLINA GIL, RAÚL

UNIVERSITAT DE VALÈNCIA (ESPAÑA) raul.molina@uv.es

“Cruzo un Desierto”. Umbral

Cuando uno se adentra en el estudio de la última poesía, no es solo que tenga la sensación de que la arena se le escapa de las manos, sino que de algún modo debe señalizar un rumbo (más o menos afortunado) por unas geografías apenas recorridas. Sobre estas frágiles y escasas huellas, pensamos que este monográfico ha podido edificar, al menos, una pequeña carretera que atraviesa sus espacios y dobleces, aunque si alguien se detiene a mirar a los costados seguirá aflorando ante él la sublime imagen del desierto, sobre el cual la senda acotada no puede sino relativizar sus dimensiones. Como sea, este número 11 de Kamchatka. Revista de análisis cultural ha cumplido su objetivo de partida: reparar los principales huecos académicos en torno a las últimas propuestas poéticas desarrolladas en España por parte de los autores y autoras nacidos en democracia. La crítica más especializada, no en vano, ya sea por su cercanía temporal con respecto a los más recientes creadores o por la avalancha indiscriminada de publicaciones, editoriales y antologías de nuevos nombres, no ha podido abordar el fenómeno con una visión global y panorámica. Creemos, sin embargo, que existen riesgos considerables en pasar por alto el análisis teórico y cultural de estas producciones poéticas cuya visibilidad está creciendo de forma exponencial. 
Aunque es recurrente el argumento de que es necesaria cierta distancia para ver con perspectiva los hechos, hay un peligro, como avisaba ya Jenaro Talens a finales de los años ochenta, en aceptar sin respuestas los comentarios, críticas y clasificaciones que en el momento de su nacimiento no se discuten desde la academia o simplemente se les ignora. Comentarios, críticas y clasificaciones que pocos años después pueden convertirse en fuentes primarias para los próximos estudiosos e historiadores, sin que se cuestione el sistema de valores o la estructura ideológica y política que rodeó su nacimiento. En esta tesitura, queremos recalcar el carácter testimonial de este monográfico y su capacidad de inscripción y afectación en dos temporalidades: en el presente, como documento que potencialmente va a intervenir en su campo de estudio, y en el futuro, como base crítica para (des)montajes posteriores. No sería exagerado decir que nuestro monográfico constituye, ahora mismo, un escaparate crítico que, como artefacto, (in)visibiliza, (des)legitima y dialoga inevitablemente con los actores del campo y, por ello, de alguna manera influye en las dinámicas de la poesía actual, lo que conlleva no poca responsabilidad.

Por si fuera poco, la ruptura interior del paradigma dominante de las últimas décadas (ya teorizado por Luis Antonio de Villena y ratificado, entre otros, por Araceli Iravedra), es evidente que ha agitado un panorama ya de por sí difícil de esclarecer. En este sentido, se han (re)activado en la actualidad una multiplicidad de propuestas y prácticas poéticas que han reformulado las relaciones y expresiones dentro de un campo escasamente cartografiado. Así las cosas, el mapa que interpreta hoy Lecturas del desierto es el de las poéticas que están surgiendo después de la dispersión del molde aglutinante de la experiencia, con la dificultad añadida de no disponer de etiquetas que agrupen los diferentes rumbos, con un objetivo tanto identificativo como editorial. Esto es, no hay todavía leyendas consensuadas para leer el mapa. Tampoco la deriva experiencial ha devenido en una disminución de las prácticas poéticas, más bien todo lo contrario: es característico de este tiempo la proliferación de premios, el surgimiento de nuevos sellos editoriales, la renovación y reformulación de las revistas de difusión de contenidos poéticos (en muchas ocasiones digitales), el aumento de los encuentros poéticos colectivos (recitales, jams, festivales, slams, etc.) o la irrupción constante de voces, nombres y propuestas que no han dejado de ampliar los márgenes del territorio (y de problematizar, con ello, su cartografía).

En definitiva, Lecturas del desierto: nuevas propuestas poéticas en España pretende, más allá de sus propios límites, incitar a un debate sobre el estatuto crítico de la más reciente poesía, que se caracteriza por no haberse cimentado en manifiestos o teorizaciones colectivas (o, al menos, no tanto como en épocas anteriores), lo cual, hasta cierto punto, ha podido determinar su cristalización textual. Aun así, como se podrá observar en los artículos de este número, ello no implica que la carga de consciencia teórica de los autores y autoras referidos sea menor, sino que, por motivos diversos, no tiene las mismas aspiraciones grupales que con anterioridad vertebraron el campo y que fomentó la dialéctica (conflictiva en distintos grados) entre las diversas corrientes y sus principales portavoces.

Por último, la ubicación de este monográfico en Kamchatka. Revista de análisis cultural ha resultado idónea para sus intereses. Primero, porque la disección a la que aspirábamos excedía el estudio filológico tradicional para desembarcar en el carácter sociológico de la escritura poética y en el análisis del texto en su doble vertiente semiótica. Basta ver al respecto cómo la propia 
revista se define en tanto espacio desde el que analizar y valorar críticamente aquellos gestos y discursos que exploren las zonas sensibles de las actuales sociedades y que permitan entrever la creación de nuevas dinámicas culturales. Segundo, porque la política de acceso abierto de Kamchatka (licencia Reconocimiento-NoComercial 4.0 de Creative Commons) que garantiza la difusión gratuita y libre de sus contenidos, es imprescindible para la profusión de los futuros diálogos que, a partir de estas páginas, queríamos que surgieran desde todos los ángulos de recepción.

\section{“HAY UNA LUZ REMOTA”. CRONOLOGÍA Y FUNDAMENTOS}

A los treinta y ocho años, Jaime Gil de Biedma escribió una elocuente suerte de testamento artístico y anímico anticipado dentro de su libro Poemas póstumos, "No volveré a ser joven”. En lo referente a este monográfico, somos conscientes de que conceptos empleados de forma recurrente como la novedad (que aparece en nuestro subtítulo) o la juventud constituyen expresiones problemáticas que arrendan diferentes connotaciones históricas, culturales y personales (véase la declaración de muerte poética por parte del citado Gil de Biedma). En este sentido, Lecturas del desierto: nuevas propuestas poéticas en España da cuenta de cómo han contribuido y están contribuyendo al panorama los autores y autoras (más) jóvenes, aquellos que, por edad, han publicado necesariamente toda su producción en el siglo XXI, es decir, después de la referida ruptura interior de la poesía de la experiencia que abrió un "nuevo" horizonte de posibilidades líricas en España. El significado de "nuevo" aquí empleado no implica necesariamente, sin embargo, ninguna fractura ni ruptura ni réplica vanguardista respecto al panorama anterior; solo da cuenta de la irrupción de las propuestas (más o menos continuistas, más o menos originales) de las voces poéticas jóvenes, esto es, las de la generación nacida con posterioridad al año 1978.

No por casualidad, la portada del monográfico realizada por Antonio Plaza Novoa parte de uno de los tópicos presentes en los carteles socialistas de las elecciones de 1982, el de un sol que al alba extiende su luz sobre una tierra verde, fecunda y democrática. Desde las coordenadas del presente, Plaza Novoa refracta la distorsión de ese mito esperanzador que, con el paso de los años, ha trocado el fértil prado en un paisaje de tintes más áridos, cuya orografía caótica y también efímera coincide con la sensación que suscita la poesía española actual. Ahora bien, insistimos en que un estudio sistemático como el llevado a cabo en este monográfico puede revelar huellas, rutas y tendencias reconocibles en esta poco transitada, pero bulliciosa área de la historia literaria más reciente.

Para el empeño de cartografiar dicho terreno resulta fundamental, no obstante, ser conscientes de que no hemos habitado un panorama uniforme. En otras palabras, esta cronología de poemarios publicados en el siglo XXI por parte de poetas jóvenes registra puntos de inflexión en su desarrollo. Así las cosas, en el año 2006 tiene lugar un hecho que posibilitó la apertura del campo poético a una nueva juventud creadora con garantías de continuidad: hablamos de la concesión ex aequo del "XXI Premio Hiperión de Poesía" a unos jovencísimos Ben Clark y David Leo (con 22 y 17 años respectivamente). Si bien Elena Medel y Fernando Valverde (por hablar de dos reconocidos poetas también nacidos en los ochenta) habían conseguido ya hacerse con un pequeño espacio en 2002 con Mi primer bikini (Premio Andalucía Joven) y Viento favorable (Accésit 
del Premio Hispanoamericano de Poesía Juan Ramón Jiménez), son Clark y Leo (con Los hijos de los hijos de la ira y Urbi et orbi) quienes verdaderamente abrieron ese definitivo hueco que poco a poco se ha ido agrandando con la incursión de nuevas voces, de nuevos relevos y de nuevas alternativas (al menos, en los nombres, aunque no tan claramente en sus prácticas poéticas).

El siguiente punto de inflexión coincide con la publicación en 2011 de la antología Tenían veinte años y estaban locos, coordinada por Luna Miguel. Dicho volumen se aleja de la dinámica programática de compendios anteriores, como los de Luis Antonio de Villena o José Luis García Martín, en ocasiones forzosamente planteados como una red común de temáticas o retóricas. En contraposición, Tenían veinte años y estaban locos se desprende de esa necesidad de agrupación que había atravesado las compilaciones anteriores y apuesta, como vector, por la juventud concebida como voz con entidad propia (aislada pese a su pertenencia a un mismo contexto). También en 2011 fue convocado por vez primera el Premio Nacional de Poesía Joven "Miguel Hernández", que acota el galardón por edad (no casualmente 31 años, es decir, en ese momento los nacidos en 1980), lo que podemos interpretar como una respuesta institucional (e incluso un reclamo) a la entrada en el campo, hasta cierto punto masiva dentro de sus posibilidades de lectura y difusión, de decenas de "jóvenes" creadores. Esta focalización en la juventud corre en paralelo cronológicamente a la emergencia del 15M, que implicó, como es sabido, una repolitización de los códigos sociales y culturales de esta, cuyas consecuencias no han dejado de orillar los registros simbólicos, imaginarios y expresivos, incluidos, por supuesto, los poéticos.

\section{“SERÁN CENIZA...”. EXPECTATIVAS Y SENTIDOS}

Todo monográfico parte de unas esperanzas previas y de unos planteamientos que se modifican y evolucionan a lo largo de su avance, lo cual se ve irremediablemente condicionado por los materiales de llegada, los excluidos y los ausentes. En este sentido, antes de comentar el resultado final de nuestro proyecto, quizás convendría detenernos tanto en los fantasmas como en los principales problemas que se han ido manifestando en el proceso. En primer lugar, hemos constatado, en general, una notable separación entre la producción de escritura poética y la elaboración teórica del discurso crítico, a pesar de que, a menudo, los roles de poeta e investigador se solapen. Habría que pensar la vinculación que esta separación mantiene con la comentada escasez de manifiestos o textos reflexivos que respalden las prácticas poéticas, más allá de reseñas esporádicamente publicadas, en su mayoría, en medios de difusión divulgativos. Relacionado con ello, tampoco habría que perder de vista la desconfianza hacia la retórica científica como método de aproximación y explicación de los registros poéticos por parte de sus agentes.

En segundo lugar, una de las más problemáticas cuestiones ha sido la gestión del vacío de algunas de las líneas temáticas que nos propusimos en la convocatoria original. En este sentido, reconocemos una significativa laguna en el monográfico sobre la poesía escrita en cualquiera de las otras lenguas del territorio español. A su vez, habría que destacar que el módulo temático planteado de mayor aceptación, en lo que se refiere a las propuestas recibidas, ha sido aquel que entroncaba con la disección de las poéticas más experimentales en torno al lenguaje. Se manifiesta en este sentido la predilección de valerse de una plataforma de publicación académica a la hora de reclamar y analizar las prácticas poéticas habitualmente menos visibilizadas (y de 
interpretación más exigente) en el marco de un campo literario que ha venido primando, por lo general, el discurso figurativo, especialmente en los medios de difusión de mayor alcance. Por el contrario, resulta revelador en lo que respecta a la atención investigadora, siguiendo este razonamiento, que la poesía con mayor número de consumidores (en lo analógico y lo digital) haya recibido un tratamiento reducido en cuanto al número de contribuciones. En paralelo, este monográfico desarrolló como vía temática, ya desde el inicio, la indagación en las poéticas periféricas o contrahegemónicas. Finalmente, sin embargo, no han recibido el interés esperado, lo que reproduce así los habituales moldes y resistencias de la crítica a poner el foco, por ejemplo, sobre las poéticas que explicitan sujetos migrantes, sobre la actualización (o no) de la llamada poesía de la conciencia crítica o sobre los relatos poéticos que los nuevos planteamientos feministas están llevando a cabo. Sea como sea, Lecturas del desierto supone un espacio dialógico que ha facilitado el cruce de diferentes voces que, desde su recurrencia o excepcionalidad, sin duda dejan constancia de los temas que la crítica académica aspiraba a abordar desde una perspectiva de análisis cultural. Dicho de otro modo, el monográfico se ha construido desde un mutuo interés entre las propuestas de sus coordinadores y la elección propia de las propuestas aquí recogidas.

No podemos olvidar, además, que una de las singularidades de este monográfico reside en su coordinación colectiva. Tres coordinadores, con tres posiciones diferentes ante lo que es o debe ser la poesía contemporánea y que, por tanto, han debido poner a dialogar sus propias ideologías literarias, con el objetivo de cubrir los territorios de un mapa desbordante, debatir sobre las propuestas de los autores y autoras, problematizar el estatuto mismo de la poesía actual, desgranar sus líneas temáticas, de fuerza, etc. Así las cosas, el resultado puede ser concebido, hasta cierto punto, como un pequeño oasis analítico tendido ante el investigador que se adentre en estas dunas, aunque será solo ceniza (o un espejismo, si se quiere) si la solidez de estos acercamientos no deviene en cimiento de futuras aproximaciones que continúen abordando las prácticas poéticas más recientes, máxime cuando estas no dejan de multiplicarse. Al fin y al cabo, la cartografía de este desierto se orienta como documento de futuro.

\section{“Y SÉ QUE NO ESTOY SOLO”. ORDENACIÓN Y LECTURA(S)}

Huelga decir que los artículos que conforman el presente monográfico han sido seleccionados a través de un riguroso proceso de evaluación por pares ciegos que ha retirado de la versión final no pocas propuestas, que, sin embargo, han contribuido a proyectar un imaginario más certero sobre el campo de estudio y sobre sus potenciales derivas. Desde estas páginas, queremos agradecer el interés mostrado por todos los autores, autoras, evaluadores y evaluadoras que han participado de un modo u otro en el proceso. Partiendo de sus investigaciones, proponemos aquí una doble posibilidad de lectura de los artículos: bien de manera independiente, bien de manera lineal, siguiendo una encadenación argumentada de los debates que emergen en sus páginas (por afinidad, por especialización o por contraste).

Ante el peligro de entender la poesía actual como una cesura y con el fin de precisar las continuidades y rupturas que se aprecian en sus discursos con respecto a la cronología inmediatamente anterior, hemos decidido abrir el monográfico con la sección titulada "Para un 
debate previo", conformada por dos señeros textos de Araceli Iravedra y Antonio Orihuela. En este sentido, la contribución de Araceli Iravedra, "El compromiso después del compromiso. Poesía, democracia y globalización (1980-2005) (extracto)", que sirvió de estudio preliminar a su volumen homónimo (UNED, 2010), realiza un exhaustivo sondeo de las poéticas más relevantes de los últimos treinta años a partir del concepto de compromiso. De forma complementaria, el artículo de Antonio Orihuela, titulado "El traje nuevo del emperador: endogamia, nepotismo, clientelismo, ídolos y mitos en la trastienda de la poesía española contemporánea", propone un recorrido por la literatura española desde la aparición de los novísimos hasta el soporte virtual de la poesía actual, en el que desentraña los mecanismos de producción de hegemonía en el espectro poético desde una asumida posición periférica.

Tras este pórtico, el primero de los artículos de investigación es "Antologuemos: tendencias, inercias y derivas de las últimas antologías poéticas en la España contemporánea", de Raúl Molina Gil, quien, desde la concepción del hecho antológico como herramienta definitoria de la historia de la poesía española reciente, proyecta una genealogía de las antologías poéticas con el fin de explicar el papel que han tenido estos compendios en los procesos de canonización del campo estudiado. Dado el alargado abanico temporal que maneja, hemos dispuesto este artículo como obertura de la sección. La segunda pieza del mismo, "Nuevas formas de expresión en la lírica reciente: el lenguaje literario y la ruptura del horizonte de expectativas", constituye una reflexión filológica pormenorizada, por parte de José Ángel Baños Saldaña, acerca de cómo se construye la fragmentación del discurso de vanguardia en un corpus de textos de poetas nacidos en torno a los ochenta. Sin salir de esta órbita de fechas, Paul Cahill indaga en su artículo "No existen mapas para estos territorios: Rubén Martín (Díaz) y la topografía estética de la poesía española reciente" en dos poéticas concretas a partir de un juego borgiano entre Rubén Martín Díaz (1980) y Rubén Martín (1980), lo que le permite explorar la cartografía estética de dos autores coetáneos vehiculados por la coincidencia de su firma. Mario Martín Gijón mantiene el foco cronológico de la contribución anterior para dilucidar de qué forma el tópico del descrédito de la vanguardia ya no es efectivo tras la disolución de la poesía de la experiencia en su estudio “Sobre una 'poesía que se piensa en el lenguaje’. ¿Hacia una nueva vanguardia en la poesía española?”. Precisamente Ewa Smilek se centra en la labor de este último autor, Mario Martín Gijón, como poeta heterodoxo que podría ilustrar sus propios postulados. El artículo “(Pa)labra[r] (en) el texto. Lector/autor en la poesía rupturista de Mario Martín Gijón” incide en la importancia de las poéticas individuales en un tiempo donde estas - defiende- han comenzado un proceso de floración.

En “'La alegre libertad en la catástrofe': tensiones entre lenguaje y verdad en la poesía española joven (2011-2018)" Álvaro López Fernández avanza en la línea temporal del artículo anterior de Mario Martín Gijón para desglosar la experimentación con el lenguaje que se produce en poemarios publicados desde 2011 hasta 2018, a través de la relación con la verdad que manifiestan (meta)textualmente varios de sus autores. Con ello, reactualiza el viejo debate sobre la poesía entendida como conocimiento o comunicación en las coordenadas del siglo XXI. De forma similar, Pablo López Carballo se centra en la complejidad comunicativa de la poesía rupturista en "A favor no es en contra; en contra es a favor. Poesía y comunicación en la actualidad", donde ahonda en la obra señera de varias autoras recientes. Con el artículo de 
Guillermo Molina Morales, "Lenguaje y poder en la poesía de María Salgado y de Ángela Segovia”, el debate de la comunicación se (re)orienta ahora a la representación de las dinámicas de poder en dos de las poéticas actuales más destacadas y experimentales que, además, tienen una dimensión performativa como elemento adicional de significación.

Por su parte, Diana Cullell, en el artículo “¿De lo bélico a lo poético? El poetry slam y su lucha feroz en defensa de la poesía", centra su objetivo en el fenómeno del poetry slam, más concretamente en la puesta en escena de sus combates poéticos, y en el papel que adquieren sus representantes, no solo como firmantes, sino como portavoces corporeizados de sus textos. En relación con esta centralidad de la corporalidad, el artículo de Ángela Martínez-Fernández "Primero el cuerpo y luego el libro: Voces del extremo. Antología (2012-2016) o cómo continuar poniendo delante del capital otra imaginación política" reflexiona en torno a la continuidad, en la última década, de la propuesta colectiva y marginal Voces del Extremo como ejercicio contrahegemónico. En contraposición, el artículo de Laura Scarano "Lugares que tienen una herida que sangra: las geografías interiores de Fernando Valverde" analiza una de las inercias más intimistas de las poéticas experienciales del nuevo milenio. En el seno de este debate entre el compromiso entendido de forma colectiva o individual, profundiza el artículo de Javier Mohedano "Deixis, cuerpo e intemperie: la gramática del nuevo compromiso poético en Erika Martínez" desde los vínculos entre presencia corporal, paisaje y política. Al hilo de estas reflexiones sobre el cuerpo como generador primero del discurso, brota precisamente la contribución de Ana Cánovas, "Cuerpos, sexualidad e identidad femenina: la poesía de María Sánchez (1989), Luna Miguel (1990) y Elvira Sastre (1992)”, que trabaja desde una perspectiva feminista con tres de las propuestas más leídas e influyentes del panorama actual. Indaga desde ahí en la relación que se establece entre el hablante lírico femenino y su sexualidad, la maternidad y la naturaleza. Algunas de estas autoras se han caracterizado especialmente por explotar las posibilidades del medio digital para la difusión poética. En torno a este fenómeno, el artículo de Luis Bagué, "Atrapados en la red: los mundos virtuales en la poesía española reciente", examina la relación entre la utilización de las herramientas virtuales y la escritura y difusión poéticas. Esto es, cómo el ciberespacio está creando (o no) una nueva red estructural con un corpus sucesivo de autores y autoras nacidos desde los años ochenta hasta mediados los noventa.

Para dar mayor cohesión al número coordinado, en la sección "Reseñas", de manera excepcional en la política de Kamchatka. Revista de análisis cultural, hemos recogido la recensión de cinco estudios críticos de reciente publicación cuya consulta a la hora de aproximarnos al panorama poético actual resulta ineludible. Así las cosas, Javier Mohedano Ruiz ha revisado el volumen Palabra heredada en el tiempo. Tendencias y estéticas en la poesía española contemporánea (Akal, 2016), coordinado por Remedios Sánchez. Jesús Murillo Sagredo se ha encargado de la lectura crítica del libro de Fernando Barbero Carrasco Palabras de barricada. Una recopilación de anarcoversos (Queimada, 2015). Cristina Pérez Gisbert, por su parte, se ha ocupado de La musa a la deriva, de Pedro Antonio González Moreno (Junta de Castilla y León, 2016). El estudio de Vicente Luis Mora, El sujeto boscoso. Tipologías subjetivas de la poesía española contemporánea entre el espejo y la notredad (1978-2015) (Iberoamericana/Vervuert, 2016), ha sido reseñado por Ariadna Álvarez Gavela. Por último, José María García Linares ha hecho lo propio con el compendio editado por Alberto García-Teresa El verso por asalto. Poesía, desobediencia y construcción antagonista (Tierradenadie, 2017). 


\section{“A MODO DE ESPERANZA” O DE CONCLUSIÓN}

El proyecto de Lecturas del desierto no se agota, sin embargo, en las investigaciones reunidas en el monográfico. Junto a ellas, pero estrechamente vinculada, presentamos una extensa antología que recoge la voz de muchos de los participantes del campo poético más reciente. No se trata, en absoluto, de crear un nuevo canon o de apostar por una tendencia u otra del espectro actual, sino de completar la cartografía crítica que ofrecemos en los artículos con un documento de peso, en el que pueda leerse, por una parte, una selección de la obra de 47 poetas que, pensamos, representan adecuadamente las corrientes y tensiones que jalonan el panorama actual; y por otra parte, una extensa reflexión sobre la poesía actual a través de una encuesta colectiva en torno a su propia producción y a las características del medio editorial y cultural en el que se inscriben. El empeño de ilustrar los múltiples espacios del territorio que nos ocupa resulta imposible, al fin y al cabo, si no cedemos el foco y atendemos a los autores y autoras como sujetos y no solo como objetos del estudio poético. En este sentido, confiamos en que el contraste entre las respuestas de sus entrevistas, además de ahondar en los posibles puntos ciegos (y arrojar más luz sobre los visibles) que hayan quedado pendientes en el monográfico, llegue a entenderse, en su conjunto, como una aproximación en torno a la creatividad poética en la España actual. Por todo ello, y vista la magnitud y la variedad (artículos, reseñas, antología y entrevistas) de los materiales que hemos organizado sobre estas dunas del presente, así como la solidez de sus planteamientos, resulta difícil para nosotros no leer estas páginas sobre poesía actual "a modo de esperanza".

Lecturas del desierto: nuevas propuestas poéticas en España no hubiera sido posible sin la ayuda a lo largo de estos meses de Jaume Peris Blanes, David Becerra, Enrique Falcón, Alberto GarcíaTeresa, Araceli Iravedra, Elena López Silva, Luis Martín-Estudillo, Antonio Méndez Rubio, Luis Muñoz, Antonio Orihuela, Gema Palacios, Cristian Piné, Óscar Pirot, Antonio Plaza Novoa y David Trashumante. Evidentemente, es necesario destacar aquí a quienes han participado en este número con artículos académicos, con reseñas, con entrevistas o con sus poemas en la antología que hemos preparado. Y, por supuesto, al equipo humano de Kamchatka: Jaume Peris Blanes, de nuevo, Tony García del Río, Núria Lorente Queralt y Karolina Zygmunt. Gracias, por tanto. 